\title{
Buck-based DMPPT emulator: a helpful experimental demonstration unit
}

\author{
Marco Balato ${ }^{1}$, Annalisa Liccardo ${ }^{1}$, Carlo Petrarca ${ }^{1}$, Francesco Bonavolontà ${ }^{1}$ \\ ${ }^{1}$ Department of Electrical and Information Technologies, University of Naples Federico II Via Claudio 21, Napoli (NA), Italy
}

\section{ABSTRACT}

Distributed control strategy represents the most promising solution to enhance the lackluster energetic performance of mismatched PhotoVoltaic (PV) systems. Moreover, many factors that contribute to such poor performance are still to be explored. To fully understand the advantages offered by the Distributed Maximum Power Point Tracking (DMPPT) approach, the implementation of a DMPPT emulator is necessary. Based on the above needs, this paper describes the realization and use of a Buck-based DMPPT emulator and shows its high flexibility and potential. The realized device is capable to emulate the output current vs. voltage (I-V) characteristics of many commercial PV modules with a dedicated Buck DC/DC converter not only in controlled atmospheric conditions but also with different currents rating of the switching devices. The system implementation is based on a commercial power supply controlled by a low-cost Arduino board. Data acquisition is performed through a low-cost current and voltage sensor by using a multichannel board by National Instruments. Experimental results confirm the validity and potential of the proposed DMPPT emulator.

\section{Section: RESEARCH PAPER}

Keywords: Distributed maximum power point tracking; mismatching; PV emulator

Citation: Marco Balato, Annalisa Liccardo, Carlo Petrarca, Francesco Bonavolontà, Buck-based DMPPT emulator: a helpful experimental demonstration unit, Acta IMEKO, vol. 10, no. 2, article 4, June 2021, identifier: IMEKO-ACTA-10 (2021)-02-04

Section Editor: Ciro Spataro, University of Palermo, Italy

Received December 15, 2020; In final form May 1, 2021; Published June 2021

Copyright: This is an open-access article distributed under the terms of the Creative Commons Attribution 3.0 License, which permits unrestricted use, distribution, and reproduction in any medium, provided the original author and source are credited.

Corresponding author: Marco Balato, e-mail: marco.balato@unina.it

\section{INTRODUCTION}

The world is currently in a dramatic climate crisis due to the growth of greenhouse gas emissions. To reduce climate change, a sustainable energy transition, oriented to the achievement of the carbon neutrality, is needed. In this direction, the total production of electricity, using renewable energy sources, represents the main goal.

To increase the distributed green energy generation, PhotoVoltaic (PV) systems are among the most promising renewable sources. In PV applications, the heaviest working conditions, not only from an energetic efficiency point of view [1]-[5], but also from a reliability one [6]-[8], are known as "mismatching conditions". In particular, when mismatching conditions occur, due to clouds, shadows, dirtiness and/or different orientation of PV modules etc., the commonly used grid-connected PV systems, made of string of PV modules connected in parallel and feeding a central inverter (Figure 1), are ineffective [1]-[8]. Various Maximum Power Point Tracking (MPPT) control techniques have been proposed in the literature to track the MPP and force the system to work at the MPP point, including high-performance MPPT techniques [9]-[19], reconfiguration architectures and algorithms, [20]-[29] and Distributed MPPT (DMPPT) approach [30]-[41]. Among of all these techniques, the DMPPT (Figure 2) is by far the most promising solution to enhance the reduced energetic performance of mismatched PV systems [30]-[41]. Differently from the Centralized approach of Figure 1, DMPPT uses a MPPT Module Dedicated DC/DC Converter realizing the MPPT for each PV module. Nevertheless, there are still several factors limiting such performance, including the efficiency of the power stage, constraints imposed by the topology, the finite rating of silicon devices, atmospheric conditions, and the suboptimal value of string voltage [39]-[43]. The fact that many of these factors are not under our control represents a severe restriction in conducting experimental test activities when real DMPPT PV systems are considered. What emerges is the necessity of the implementation of a DMPPT emulator as a helpful tool to emulate the output $I-V$ characteristics of many commercial PV modules with a dedicated Buck DC/DC converter not only in controlled environment conditions (as it happens for common PV emulators [42]-[45]) but also with different currents rating of the switching devices. Based on the 


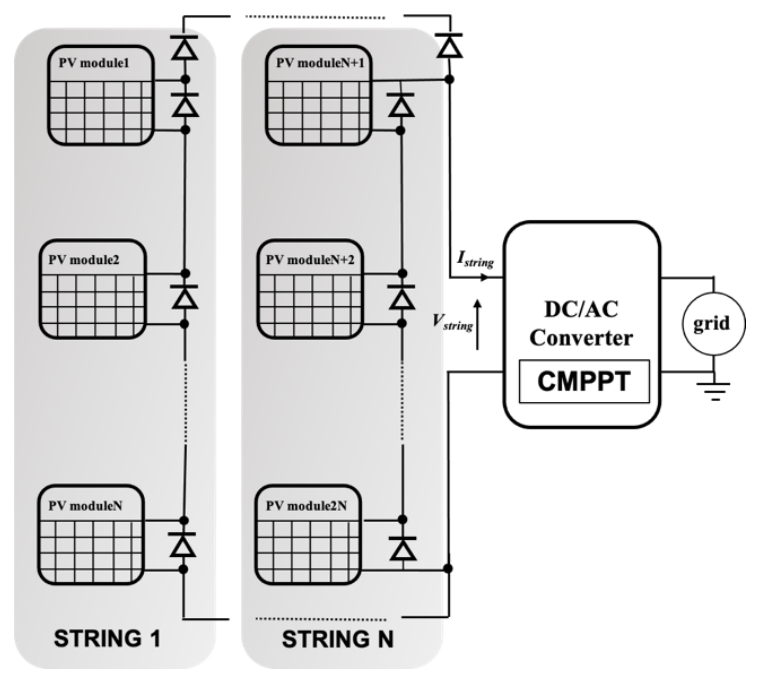

Figure 1. Commonly used grid-connected PhotoVoltaic (PV) system.

above considerations, the current study describes the realization and use of a Buck based DMPPT emulator.

The repeatability of experimental tests, the tighter control of climatic conditions, the narrowing of the gap between the physical dimensions of a PV plant and the space available in a university lab, the simplicity with which new algorithms can be tested, and the low maintenance costs are just some of the benefits offered by the emulator presented in the paper.

The proposed Buck based DMPPT emulator consists of a commercial power supply controlled by a low-cost Arduino board whose control strategy is based on a set of equations defining the mathematical model of a DMPPT device.

The present paper is organized as follows: the mathematical model of a single Buck based DMPPT unit is described in detail in Section 2; Section 3 highlights the still open issues regarding the DMPPT approach; Section 4 is dedicated to the design and description of the proposed Buck based DMPPT emulator; experiments and tests are presented in Sections 5; finally, Section 6 draws the conclusions.

\section{MATHEMATICAL MODEL OF A BUCK BASED PV UNIT}

In the following, the system shown in Figure 3 will be considered and analysed. It is composed of a PV module equipped with its own Buck DC/DC converter realizing the DMPPT function. To simplify the readability, the considered

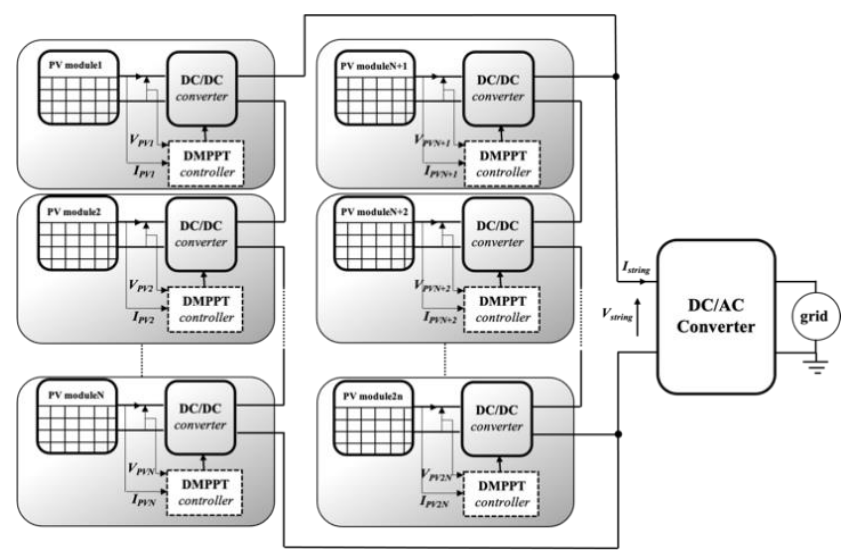

Figure 2. Commonly used DMPPT grid-connected PhotoVoltaic (PV) system.

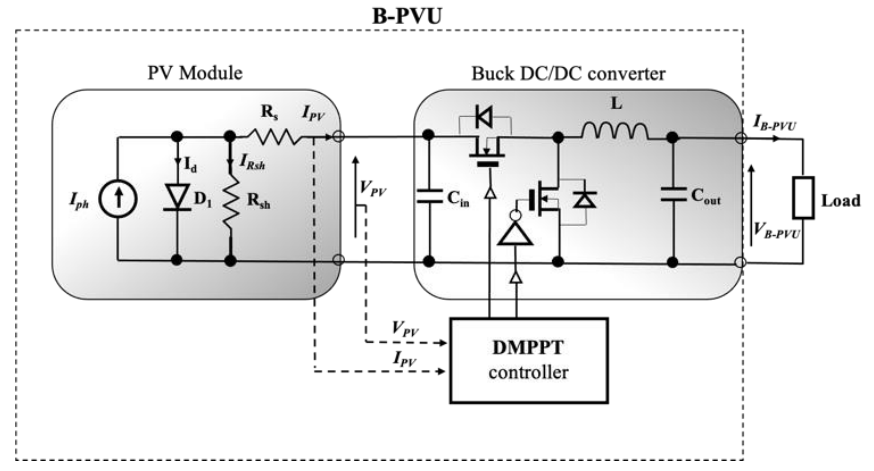

Figure 3. Circuit model of B-PVU.

system will be indicated with the acronym "B-PVU" that means Buck based PhotoVoltaic Unit.

In Figure $3, I_{\mathrm{PV}}\left(V_{\mathrm{PV}}\right)$ and $I_{\mathrm{B}-\mathrm{PVU}}\left(V_{\mathrm{B}-\mathrm{PVU}}\right)$ denote, respectively, currents (voltages) at the input and output ports of the Buck DC/DC converter. Moreover, the symbol $P_{\mathrm{PV}}$ indicates the power extracted from the PV module, while the symbol $P_{\mathrm{B}-\mathrm{PVU}}$ indicates the power at the output of the converter. The PV module is described by a single diode model, in which: the current generator represents the photo-induced current, the diode $\mathrm{D}_{1}$ takes into account the effects at the silicon $\mathrm{p}-\mathrm{n}$ junction of the PV cell; the series $\left(R_{\mathrm{s}}\right)$ and parallel $\left(R_{\mathrm{sh}}\right)$ resistances take into account the loss mechanisms taking place in the PV module due to metallic ribbon. In Figure 4, the typical output static Current vs. Voltage (I-V) characteristics of a PV module (dashed line) and of a B-PVU (bold line) are reported, at constant irradiance $(S)$ and temperature $(T)$ values. Losses occurring in the power stage of the Buck converter (switching, conduction, and iron losses) and the settling time of the step response of a closed or open loop B-PVU are neglected. In addition, the MPPT efficiency of the DMPPT controllers is supposed to be equal to one $\left(\eta_{\text {DMPPT }}=1\right)$. In these hypotheses, the output static $I-V$ characteristic of a single B-PVU is marked by the presence of three different operating regions: Best Operating Region (BOR), and two Worst Operating Regions (WOR1 and WOR2). The adjectives best and worst are not used randomly insofar as they allow to discriminate operating points with high efficiency with respect to the other ones.

Worst Operating Region 1 (WOR1): In the WOR1, defined for $0 \mathrm{~V} \leq V_{\mathrm{B}-\mathrm{PVU}} \leq V_{1}$, the output $I-V$ characteristic of the $\mathrm{B}$ PVU is flat and equal to:

$$
I_{\mathrm{B}-\mathrm{PVU}}=I_{\mathrm{DSMAX}} \cdot
$$

To explain the meaning of the voltage value $V_{1}$ some preliminary considerations are necessary. Since the Buck converter is able to lower its output voltage $V_{\text {B-PvU }}$ with respect to the input voltage $V_{\mathrm{PV}}$, and by considering that, when the PV module is working in its MPP, it must be:

$$
V_{\mathrm{B}-\mathrm{PVU}} \cdot I_{\mathrm{B}-\mathrm{PVU}}=P_{\mathrm{MPP}} \text {, }
$$

where $P_{\text {MPP }}$ is MPP power. It is evident that, as long as the PV module operating point matches the MPP, the lower the output voltage the higher the output current. By indicating with IDSMAX the maximum allowed value of $I_{\mathrm{B}-\mathrm{PvU}}$ without harming any silicon device (i.e. power mosfets) we get:

$$
V_{1}=\frac{P_{\mathrm{MPP}}}{I_{\mathrm{DSMAX}}}
$$




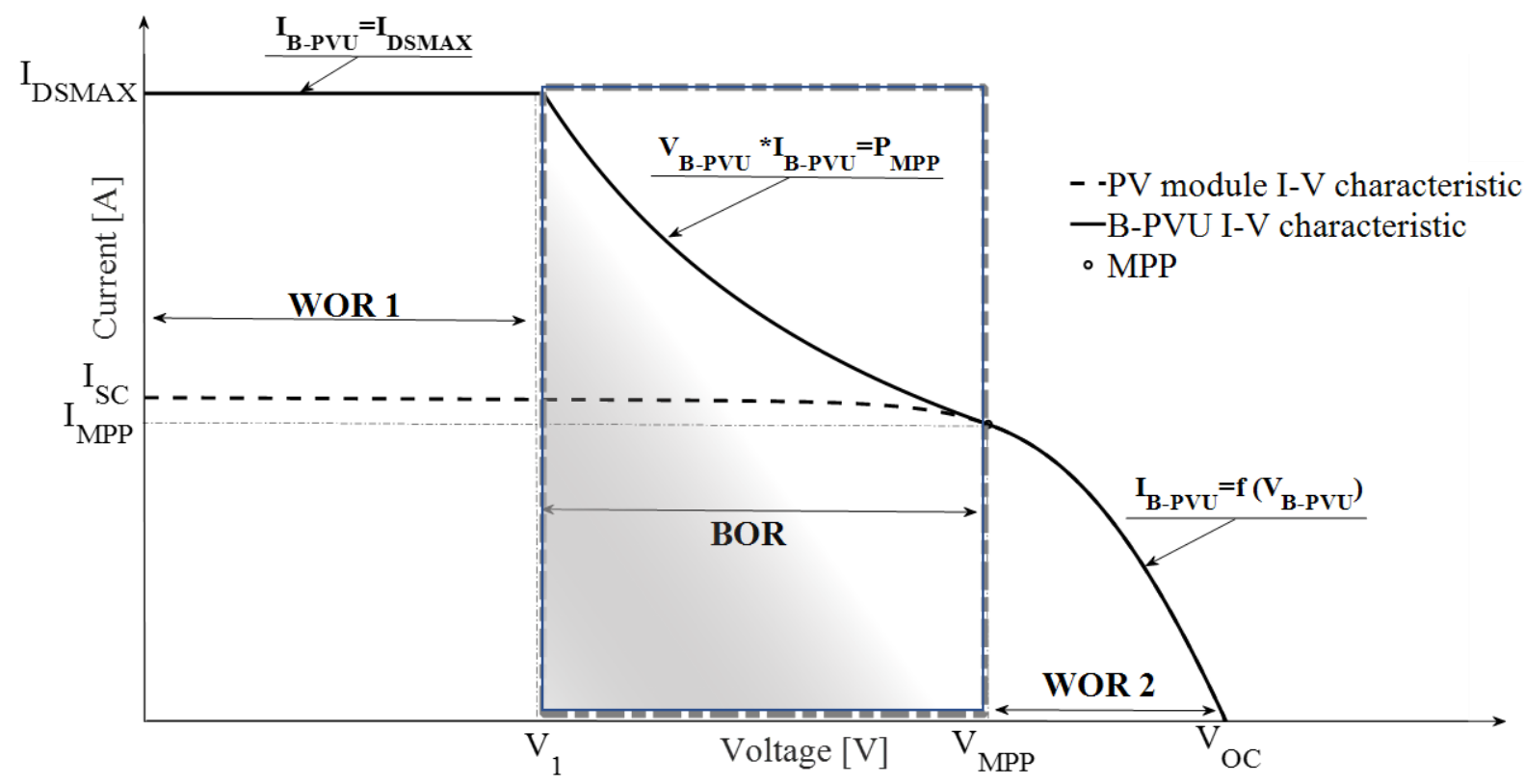

Figure 4. PV module $I-V$ characteristic and B-PVU $I-V$ characteristic.

Therefore, $V_{1}$ is the lower limit of the output voltage $V_{\text {B-PvU }}$ when the output power $P_{\mathrm{B}-\mathrm{PVU}}$ assumes its maximum value and it can be calculated by using (3) once I DSMAx is known. In practice, the information regarding the value of IDSMAx is included in the silicon devices' datasheet.

Best Operating Region (BOR): BOR, defined for $V_{1} \leq V_{\mathrm{B}-\mathrm{PVU}} \leq V_{\mathrm{MPP}}\left(\mathrm{R}_{\mathrm{BOR}-\mathrm{V}}=\left[V_{1}, V_{\mathrm{MPP}}\right]\right)$ is described by a hyperbole of (4), where $V_{\text {MPP }}$ is the MPP voltage.

$$
I_{\mathrm{B}-\mathrm{PVU}}=\frac{P_{\mathrm{MPP}}}{V_{\mathrm{B}-\mathrm{PVU}}} \text {. }
$$

As shown in Figure 4, the current range $\left(R_{B O R-I}\right)$ associated to BOR (optimal current range) is defined as follows:

$$
R_{\mathrm{BOR}-\mathrm{I}}=\left[I_{\mathrm{MPP}}, I_{\mathrm{DSMAX}}\right] \text {. }
$$

Worst Operating Region 2 (WOR2): WOR2 is defined for $V_{\text {MPP }} \leq V_{\text {B-PVU }} \leq V_{\text {OC, }}$, where $V_{\text {OC }}$ is the open circuit voltage that can be provided by the adopted PV module in the considered atmospheric conditions:

$$
V_{\mathrm{OC}}=V_{\mathrm{OC}_{\mathrm{STC}}}\left[1+\frac{\alpha_{\mathrm{V}}}{100}\left(T-T_{\mathrm{STC}}\right)\right] \text {, }
$$

where the $V_{\text {OCSTC }}\left(T_{\mathrm{STC}}\right)$ is the open circuit voltage (temperature) in the Standard Test Conditions $\left(S_{\mathrm{STC}}=1000 \mathrm{~W} / \mathrm{m}^{2}\right.$, $\left.T_{\mathrm{STC}}=25^{\circ} \mathrm{C}\right)$ and $\alpha_{\mathrm{V}}$ is the voltage temperature coefficient. In such a region, the characteristic of the controlled PV module coincides with the PV module one. In particular, for $V_{\text {MPP }} \leq V_{\text {B-PVU }} \leq V_{\text {OC, }}$ the DMPPT controller forces the Buck $\mathrm{DC} / \mathrm{DC}$ converter to work with a duty cycle equal to one. In this condition the current $I_{\mathrm{B}-\mathrm{PvU}}$ is equal to:

$$
I_{\mathrm{B}-\mathrm{PVU}}=I_{\mathrm{PV}}=I_{\mathrm{ph}}-I_{\mathrm{d}}-I_{\mathrm{Rsh}},
$$

where $I_{\mathrm{ph}}$ is the photo-induced current, which, in accordance with (8), is linearly dependent on the irradiance level (S) and the PV module temperature $(T), I_{\mathrm{d}}$ is the current in diode $\mathrm{D}_{1}(9)$, and $I_{\text {Rsh }}$ is the shunt-resistor current (10):

$$
\begin{aligned}
& I_{\mathrm{ph}}=I_{\mathrm{SC}_{\mathrm{STC}}} \frac{S}{S_{\mathrm{STC}}}\left(1+\frac{\alpha_{\mathrm{I}}}{100}\left(T-T_{\mathrm{STC}}\right)\right) \\
& I_{\mathrm{d}}=I_{\mathrm{sat}}\left(e^{\frac{V_{\mathrm{PV}}+R_{\mathrm{S}} I_{\mathrm{PV}}}{V_{\mathrm{T}}}}-1\right) \\
& I_{\mathrm{Rsh}}=\frac{V_{\mathrm{PV}}+R_{\mathrm{S}} I_{\mathrm{PV}}}{R_{\mathrm{sh}}}
\end{aligned}
$$

where $V_{\mathrm{T}}$ is the thermal voltage, $\alpha_{\mathrm{I}}$ is the current temperature coefficient and $I_{\text {sat }}$ is the diode reverse bias saturation current (11):

$$
I_{\text {sat }}=C T^{3} e^{\left(-\frac{E_{\text {gap }}}{k T}\right)},
$$

where $k=1.38 \mathrm{~J} / \mathrm{K}$ is the Boltzmann constant, $E_{\text {gap }}$ is the band gap of the semiconductor material (in the following it is assumed $E_{\text {gap }}=1.124 \mathrm{eV}$ ), and $C$ is the temperature coefficient [46]. The $I-V$ output characteristics of a single B-PVU are strictly dependent on the irradiance and temperature levels (12). Typical curves are shown in Figure 5.

$$
T=T_{\text {ambient }}+\frac{N O C T-20}{800} S .
$$

Since in real environmental conditions the temperature usually changes quite slowly with respect to variation of the irradiance level occurring during the day, all subsequent results were obtained by considering a constant value of the PV module temperature equal to $57.5^{\circ} \mathrm{C}\left(T=57.5^{\circ} \mathrm{C}\right)$ which corresponds to $T_{\text {ambient }}=25^{\circ} \mathrm{C}$.

In Figure 6, the $I-V$ output characteristics of a single B-PVU, obtained by changing both the irradiance $(S)$ and $I_{\text {DSMAX }}$ values are reported. From the Figure 5 and Figure 6 the non-stationarity behaviour of the BOR emerges, especially when time-varying atmospheric conditions occur. In particular, the higher the value of irradiance $S$, the lower the amplitude of the optimal range, assessed in terms both of the current and the voltage. $\left(R_{B O R-I}\right.$ and $R_{B O R-I}$ ). Inverse conditions occur for the value of $I_{\text {DSMAX. }}$ 


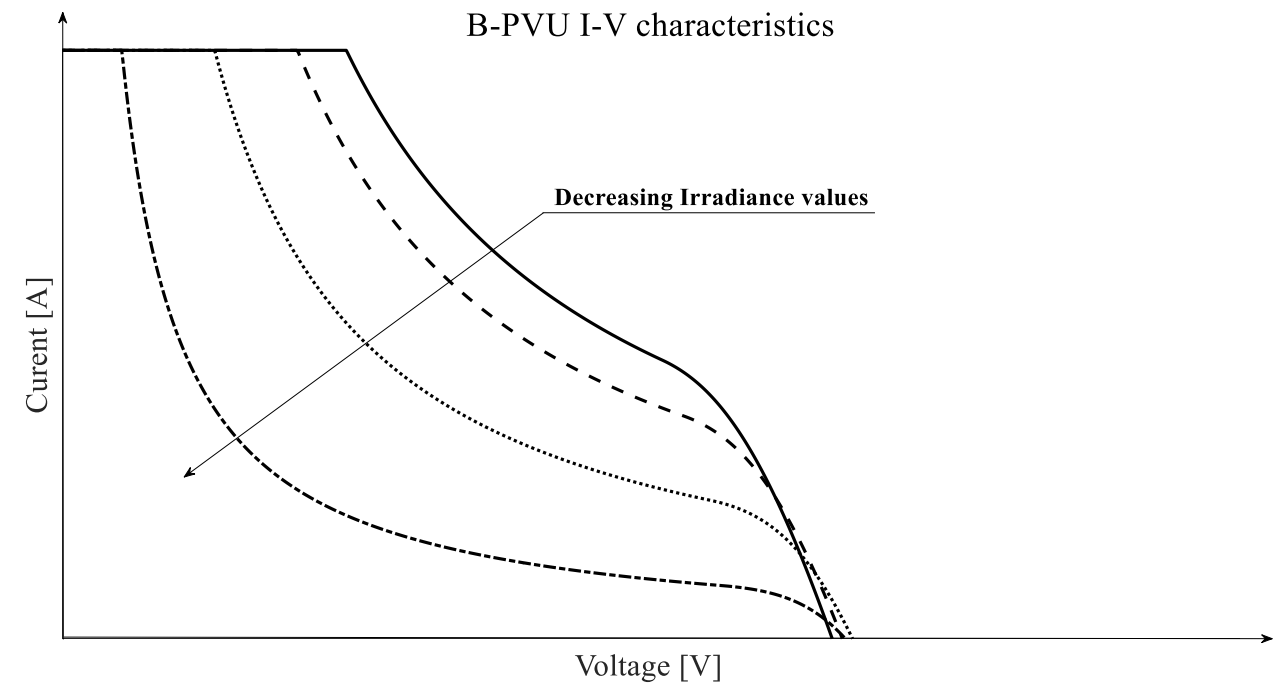

Figure 5. I-V characteristics of B-PVU.

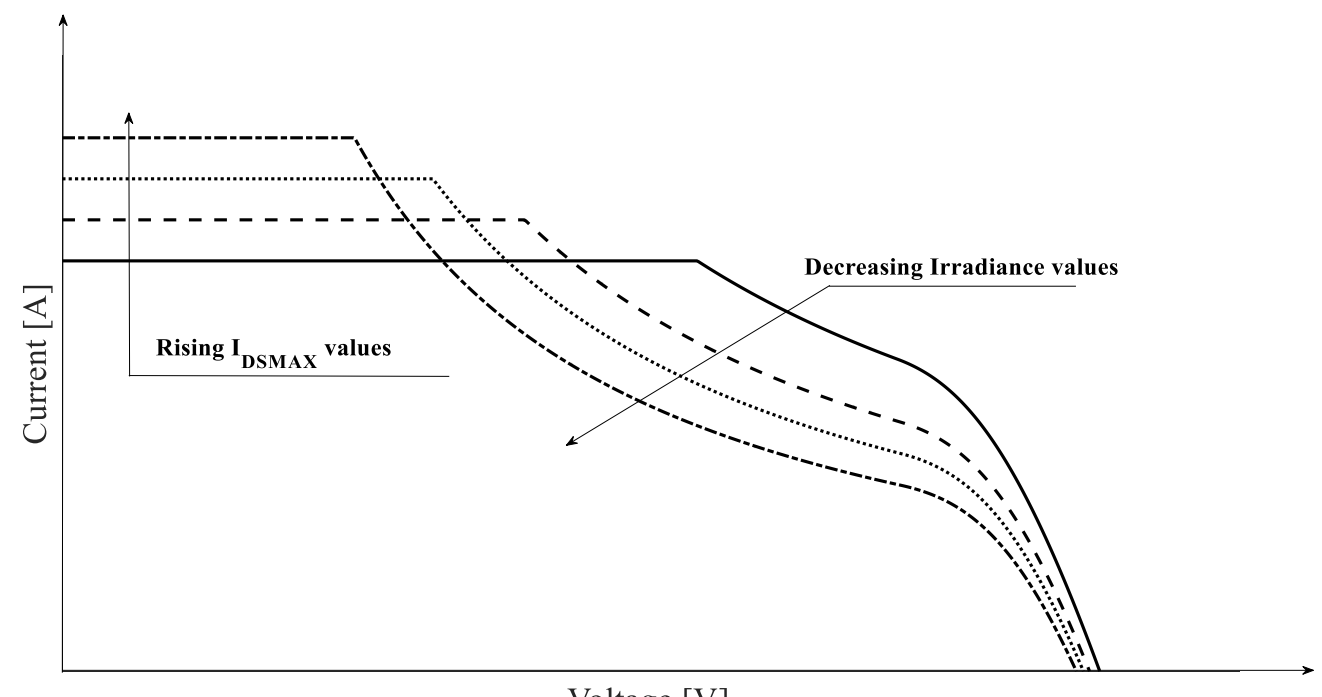

Figure 6. I-V characteristics of B-PVU.

\section{OPEN ISSUES}

In the previous section it has been shown that, under nonstationary operating conditions, the Best Operating Region (BOR) of a single B-PVU, whether assessed in terms of the current or the voltage, has time-varying characteristics (Figure 5 and Figure 6). Of course, the same considerations can be extended to more complex systems, which consist of many strings of B-PVUs connected in parallel. Without loss of generality, it is possible to consider, as a reference case, a PV system with a simple topology; in particular, a PV system, consisting of a single string of $N_{\mathrm{S}}=2 \mathrm{~B}$-PVUs (B-PVU1 and BPVU2), will be analysed in the following (Figure 7). The Standard Test Conditions (STC) parameters of the considered commercial PV module (Sunmodule SW225 [47]), are reported in Table 1.

In Figure 8, the output static Power vs. Voltage $(P-V)$ characteristics of the reference system are reported in three different mismatching scenarios and with three different values of $I_{\text {DSmax }}$ (Case I, Case II and Case III). In such cases, as shown in Figure 8, the adopted distributions of the irradiance values $(S)$ characterizing the PV modules, the values of the maximum allowed current (IDSMAx) provided by the silicon devices and the value of the ambient temperature $\left(T_{\text {ambient }}\right)$ are the following ones: $[S]=([1000 ; 800]) \mathrm{W} / \mathrm{m}^{2}, \quad I_{\text {DSMAX }}=8 \mathrm{~A} \quad$ (Case I), $[S]=([1000 ; 600]) \mathrm{W} / \mathrm{m}^{2}, I_{\text {DSMAX }}=10 \mathrm{~A}($ Case II $),[S]=([1000$; 200]) $\mathrm{W} / \mathrm{m}^{2}, I_{\text {DSMAx }}=12 \mathrm{~A}$ (Case III), $T_{\text {ambient }}=25^{\circ} \mathrm{C}$. It is worth clarifying that the $j$-th component of vector $[S]$ represents the constant irradiance value of the $j$-th PV module of the array $(j=1,2)$. In Figure 8, the three different Best Operating Regions, correspondig to the three different scenarios, are highlighted.

Table 1. SolarWorld SW 225 PV module electrical characteristics in STC, $\left(\mathrm{S}_{\mathrm{STC}}=1000 \mathrm{~W} / \mathrm{m}^{2} ; \mathrm{TsCT}=25^{\circ} \mathrm{C}\right)$.

\begin{tabular}{lr} 
STC open circuit voltage & $V_{\mathrm{OC}_{\mathrm{STC}}}=36.7 \mathrm{~V}$ \\
STC short circuit current & $I_{\mathrm{SC}_{\mathrm{STC}}}=8.13 \mathrm{~A}$ \\
STC maximum power point voltage & $V_{\mathrm{MPP}_{\mathrm{STC}}}=29.7 \mathrm{~V}$ \\
STC maximum power point current & $I_{\mathrm{MPP}_{\mathrm{STC}}}=7.59 \mathrm{~A}$ \\
Voltage temperature coefficient & $\alpha_{\mathrm{V}}=-0.34 \% / \mathrm{K}$ \\
Current temperature coefficient & $\alpha_{\mathrm{I}}=0.034 \% / \mathrm{K}$ \\
Nominal Operating Cell Temperature & NOCT $=46^{\circ} \mathrm{C}$ \\
\hline
\end{tabular}




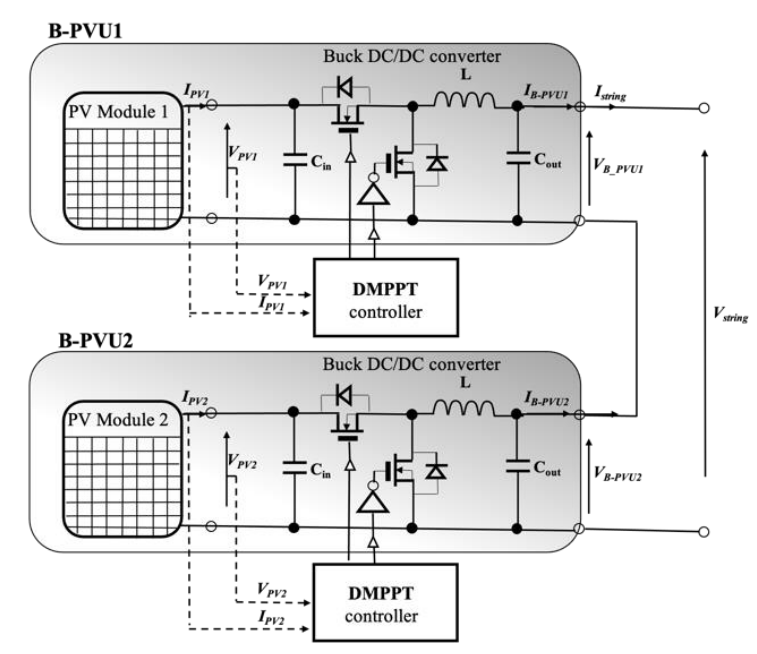

Figure 7. PV system under test.

This means that, the energetic performances of PV systems, adopting the buck based DMPPT approach, strongly depend on the value assumed by the string voltage ( $\left.V_{\text {string }}\right)$, that, necessarily, must be contained in the BOR. For such a reason, the string voltage must be considered as a variable to be controlled through a proper MPPT algorithm that acts at the output of the entire PV system. This approach is known with the acronym HMPPT that means Hybrid MPPT since it is based on the joint adoption of both Central and Distributed approaches. As a further example a more complex PV system, composed of a string of $N s=11 \mathrm{~B}$ PVUs can be considered. The $P-V$ characteristics are plotted in Figure 9 and refer to the following parameters: $[S]=([1000$; $1000 ; 1000 ; 1000 ; 800 ; 800 ; 800 ; 700 ; 700 ; 600 ; 600]) \mathrm{W} / \mathrm{m}^{2}$, $I_{\text {DSMAX }}=8$ A (Case I), $[S]=([650 ; 650 ; 500 ; 500 ; 500 ; 500 ; 400$; $400 ; \quad 300 ; \quad 300 ; \quad 200]) \mathrm{W} / \mathrm{m}^{2}, \quad I_{\text {DSMAx }}=10 \mathrm{~A} \quad$ (Case II), $T_{\text {ambient }}=25^{\circ} \mathrm{C}$. Also in this case, for an optimal energetic performance, the BOR must be continuously tracked.

The above considerations have general validity since, as shown in [38]-[40], they do not depend on the size of PV system and/or on the type of the used DC/DC converters such as Buck, Boost and Buck-Boost. Moreover, recent studies have highlighted the possibility to combine the DMPPT and reconfiguration approaches as a powerful strategy for increasing the efficiency of PV systems [41]. This means that the opportunities offered by the DMPPT approach are still to be explored. To fully understand their benefits, it is necessary to have access to a tool, able to emulate not only the $I-V$ characteristic of a single B-PVU but also of a string of generic

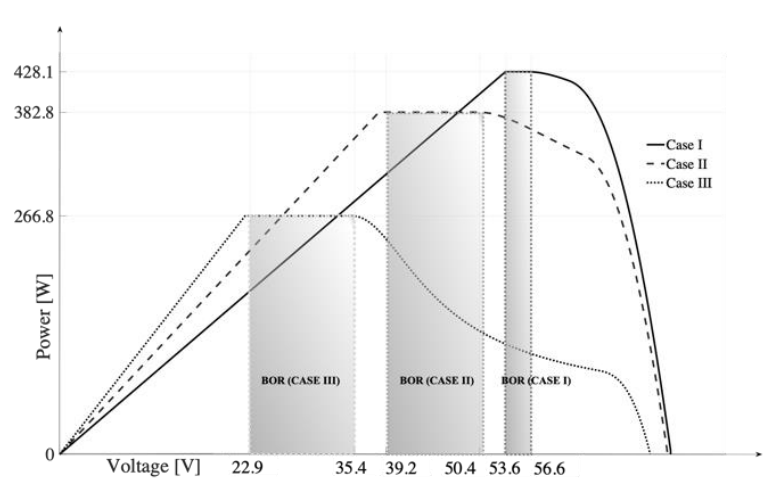

Figure 8. P-V characteristics of a string of two B-PVUs.

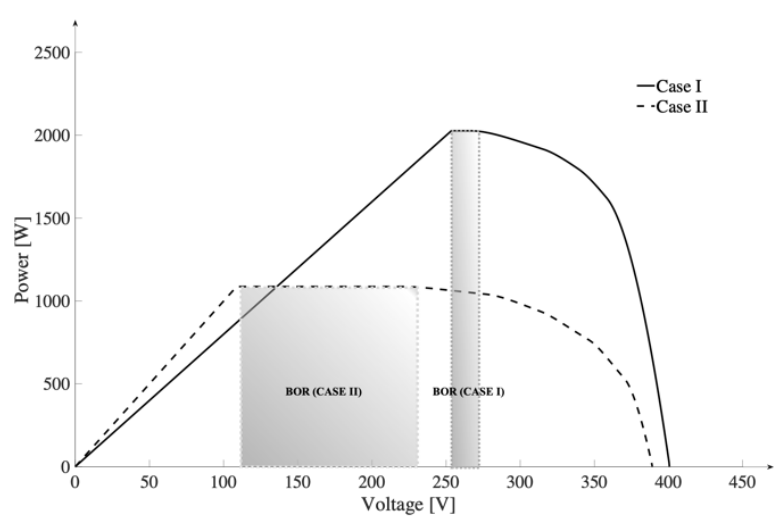

Figure 9. P-V characteristics of a string of eleven B-PVUs.

number of B-PVUs, in controlled atmospheric conditions and with different values of $I_{\text {DSMAx }}$. The possibility to swap the value of IDSMAx allows the emulation of many Buck converters commercially available, which results in a consistent reduction in time and cost. It is expected that the proposed tool will give new impetus to the advance in PV applications since it represents a useful incentive for both development and testing of new MPPT algorithms suitable for DMPPT implementation. Moreover, it is possible to experimentally validate the performances offered by the joint adoption of DMPPT and reconfiguration approaches. The newly emerged concepts represent the main motivations that pushed the authors to the development of an experimental demonstration unit based on the Buck DC/DC converter. The proposed emulator is unique as confirmed by the absence both in literature and on the market of an equivalent device, able to emulate the $I-V$ characteristic of a DMPPT unit based on the Buck converter.

\section{IMPLEMENTATION OF B-PVU EMULATOR}

A block diagram of the proposed B-PVU emulator is shown in Figure 10. It consists of three fundamental blocks: Power Block (PB), Control Block (CB) and Acquisition Block (AB).

Power Block (PB): $\mathrm{PB}$ is realized by means of two commercial power supplies (Kepco BOP 100-4 [48]). One represents the power stage of the B-PVU emulator and is used as a current-controlled source whose output current $I_{\mathrm{PVU}}(t)$ is regulated by means of a proper controller. The other power supply is used to obtain a controlled electronic load able to properly scan the $I-V$ characteristics of the B-PVU emulator. The two power supplies are suitable to work in all four quadrants of the current-voltage plane. They are linear power supplies with two bipolar control channels (voltage or current mode), selectable and individually controllable by either front panel controls or remote signals. The input signal of the $\mathrm{PB}\left(S_{\text {ref }}(t)\right)$ is achieved based on the following equation:

$$
S_{\text {ref }}(t)=S(t) \cdot I_{B-P V U}
$$

where $S(t)$ represents the time varying irradiance value. Concerning the value of $I_{\mathrm{B}-\mathrm{PvU}}$, it is obtained according to (1), (4) and (7).

Control Block (CB): CB consists of controlling and conditioning units. The embedded board "Arduino Mega 2560" is used as controlling unit. The "Arduino Mega 2560" is powered via a USB connection and provides 54 digital input/output pins (15 of which can be used as PWM outputs) and 16 analog inputs, and it can be programmed through Arduino IDE software [49]. 


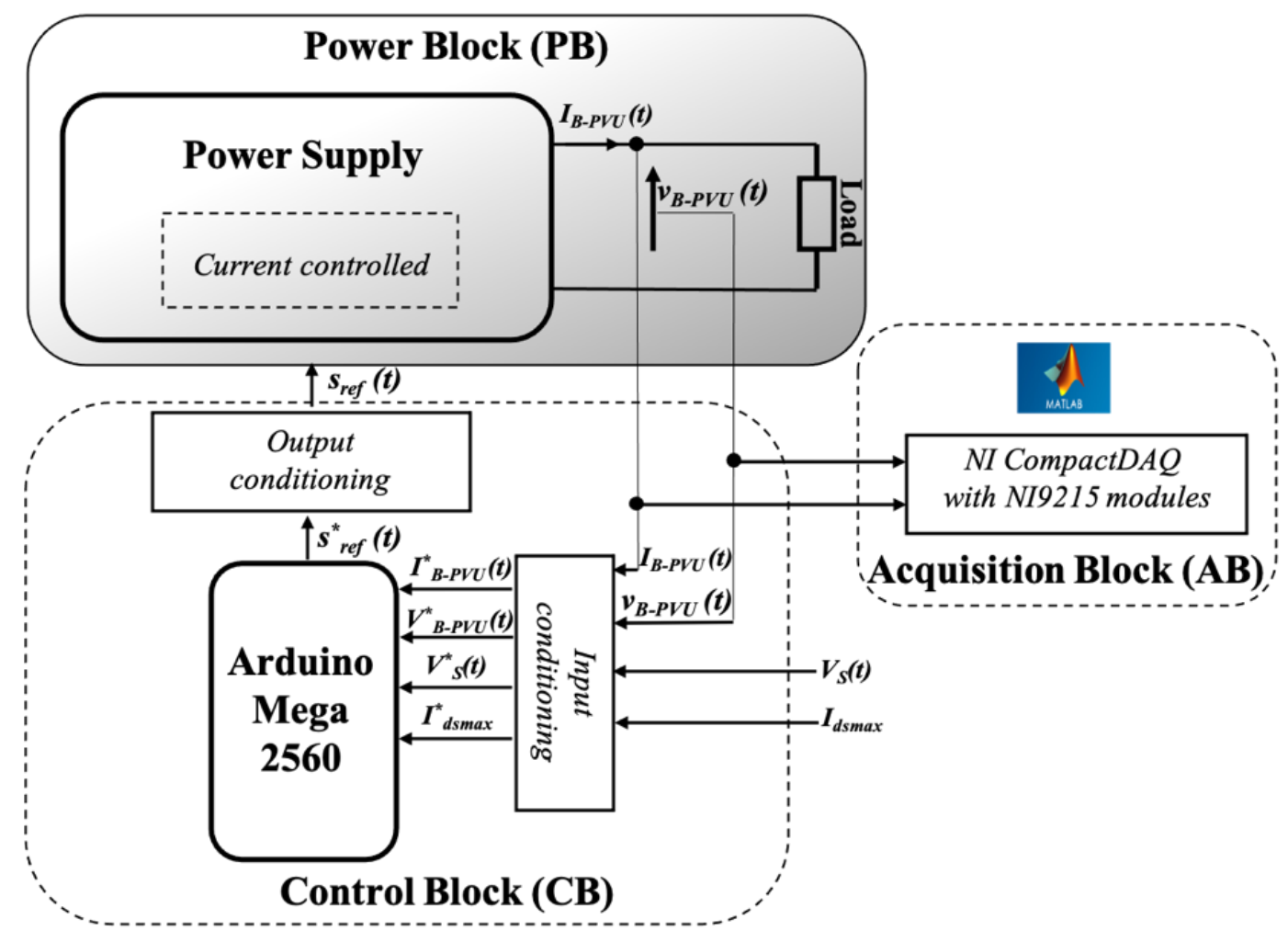

Figure 10. Block diagram of proposed B-PVU emulator.

The analog input signals of the microcontroller, which are marked with an asterisk (Figure 10), represent a scaled version of the corresponding signals $V_{\mathrm{B}-\mathrm{PVU}}(t), I_{\mathrm{B}-\mathrm{PVU}}(t), V_{\mathrm{S}}(t)$ and $I_{\mathrm{DSMAX}}$. Such scaling is necessary to adapt the electrical characteristics of such signals to the limited range $[0,5] \mathrm{V}$ of the microcontroller. Regarding the conditioning units, they are divided in: (a) the input conditioning unit and (b) the output conditioning unit. The input condition unit consists of a voltage (current) sensor for sensing and adapting the PVU output voltage $\left(V_{\mathrm{B}-\mathrm{PVU}}(t)\right)$ (current $\left.I_{\mathrm{B}-\mathrm{PVU}}(t)\right)$ to the maximum allowed input voltage $\left(V_{\mathrm{B}-\mathrm{PVU}}^{*}(t)\right.$ and $\left.I_{\mathrm{B}-\mathrm{PVU}}^{*}(t)\right)$ and a National Instruments generation board (BNC2100 series connector blocks), which is used to reproduce the input signals $V_{\mathrm{S}}^{*}(t)$ and $I_{\text {DSMAX. To configure the data generation }}^{*}$ hardware (BNC-2100 Series Connector Blocks) MATLAB data acquisition toolbox is used.

The Arduino's input signals must fulfil the following equations:

$$
\begin{aligned}
& V_{B-P V U}^{*}(t)=5 \cdot \frac{V_{B-P V U}(t)}{V_{M A X}} \in[0,5] \mathrm{V} \\
& I_{B-P V U}^{*}(t)=5 \cdot \frac{I_{B-P V U}(t)}{I_{M A X}} \in[0,5] \mathrm{V} \\
& \mathrm{V}_{\mathrm{S}}^{*}(\mathrm{t})=5 \cdot \frac{\alpha_{\mathrm{S}} \cdot \mathrm{S}(\mathrm{t})}{\mathrm{S}_{\mathrm{STC}}} \in[0,5] \mathrm{V} \\
& I_{\mathrm{DSMAX}}^{*}=5 \cdot \frac{I_{\mathrm{DSMAX}}}{I_{\mathrm{MAX}}} \in[0,5] \mathrm{V} .
\end{aligned}
$$

where $V_{\mathrm{MAX}}=100 \mathrm{~V}$ and $I_{\mathrm{MAX}}=4 \mathrm{~A}$ are the maximum allowed values of the output voltage and current from the power unit: $\alpha_{\mathrm{S}}=1 \mathrm{~V} \mathrm{~m} \mathrm{~m}^{2} / \mathrm{W}$. The adopted current sensor is an "INA169 current sensor module", which is a high-side, unipolar, current shunt monitor, that allows the measurement of continuous current up to $5 \mathrm{~A}$. To reduce the PVU output voltage up to 10 times compared to the original, a voltage divider formed by two resistances of $220 \mathrm{k} \Omega$ and $11.5 \mathrm{k} \Omega$, respectively, was adopted as a voltage sensor. At the end, the output conditioning unit consists of a Digital Analog Converter (DAC) "Adafruit MCP4725".

Acquisition Block (AB): AB consists of a commercial National Instruments multichannel USB data acquisition system (NI CompactDAQ with NI9215 modules characterized by $16-$ bit resolution and maximum sampling frequency of $100 \mathrm{kS} / \mathrm{s}$ ) that allows to back up the experimental data in Matlab environment.

The experimental setup was designed and built in the Circuit Laboratory of the University of Naples Federico II and is shown in Figure 11.

In Table 2, the electrical characteristics of the proposed BPVU emulator are reported.

To verify the performances of the proposed emulator, a preliminary test activity on the system composed of a microcontroller "Arduino Mega 2560" and a DAC "MCP4725" has been carried out. In particular, two different Operating Conditions (OC1 and OC2) have been chosen, corresponding to different mismatching scenarios.

OC1 refers to the following parameters: $S=200 \mathrm{~W} / \mathrm{m}^{2}$, $T_{\text {ambient }}=25^{\circ} \mathrm{C}$, and to two different values of the maximum allowed current ( $I_{\mathrm{DSMAX}}=4 \mathrm{~A}$ and $I_{\mathrm{DSMAX}}=3 \mathrm{~A}$, respectively). The oscilloscope (Tektronix MDO 3034) screenshots shown in

Table 2. Electrical characteristics of the proposed B-PVU emulator

\begin{tabular}{lc}
\hline Maximum output Current & $I_{\mathrm{B}-\text { PVUmax }}=5 \mathrm{~A}$ \\
\hline Maximum output Power & $P_{\mathrm{B}-\text { PVUmax }}=150 \mathrm{~W}$ \\
\hline Maximum output Voltage & $V_{\mathrm{B}-\text { PVUmax }}=36 \mathrm{~V}$ \\
\hline
\end{tabular}




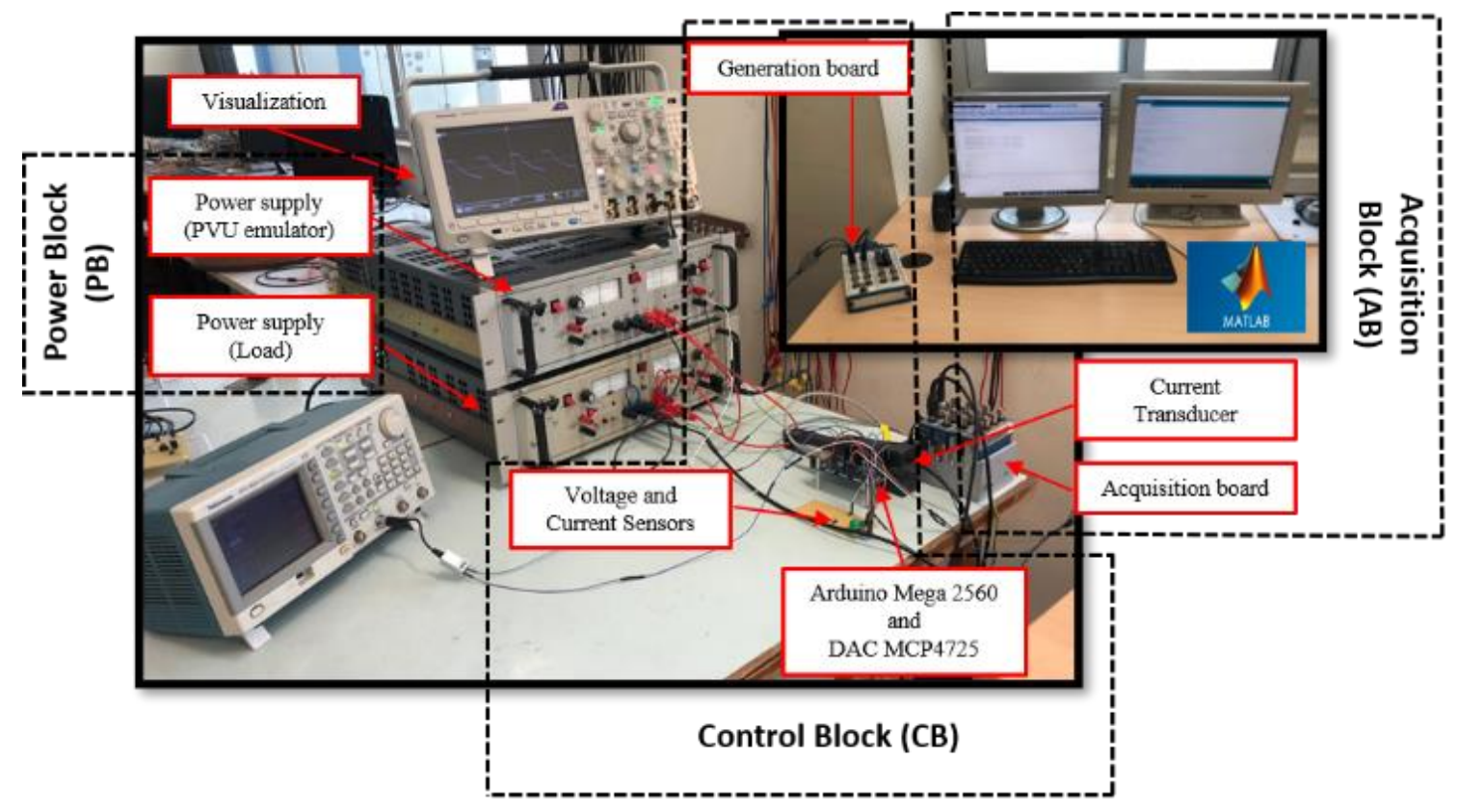

Figure 11. Experimental setup of proposed B-PVU emulator.

Figure 12 represent the (I-V) output characteristics of the emulator for $I_{\mathrm{DSMAX}}=4 \mathrm{~A}$ (turquoise curve) and for $I_{\text {DSMAX }}=3 \mathrm{~A}$ (pink curve). The $I-V$ characteristic of the proposed B-PVU emulator have been scanned by applying a periodic (frequency $1 \mathrm{~Hz}$ ) ramp signal (yellow curve of Figure 12) at the microcontroller input $V_{\text {B-PvU }}^{*}(t)$. The amplitude of the adopted ramp signal varies from $0 \mathrm{~V}$ to $1.66 \mathrm{~V}$ which corresponds to the B-PVU ramp voltage $V_{\mathrm{B}-\mathrm{PVU}}(t)$ ranging from $0 \mathrm{~V}$ to the open circuit voltage $V_{\mathrm{OC}}$ at $T=57.5^{\circ} \mathrm{C}\left(V_{\mathrm{OC}}=33 \mathrm{~V}\right.$ in (12).

The comparison of the experimental characteristic obtained when $I_{\text {DSMAX }}=4 \mathrm{~A}$ (turquoise curve) with the theoretical one (white curve) shown in Figure 13 confirms the excellent capability of the emulator.

The output characteristics have also been obtained in a different Operating Condition (OC2). It refers to the following parameters: $T_{\text {ambient }}=25^{\circ} \mathrm{C}, I_{\mathrm{DSMAX}}=3 \mathrm{~A}$ and to two different values of irradiance $\left(S=300 \mathrm{~W} / \mathrm{m}^{2}\right.$ and $S=200 \mathrm{~W} / \mathrm{m}^{2}$, respectively). The oscilloscope screenshots of Figure 14 represent the $(I-V)$ characteristics when $S=300 \mathrm{~W} / \mathrm{m}^{2}$ (turquoise curve) and $S=200 \mathrm{~W} / \mathrm{m}^{2}$ (pink curve).

To fully explore the potentialities of the proposed emulator, in Figure 15, the time-domain behaviour of the signal $S_{\text {ref, }}^{*}$

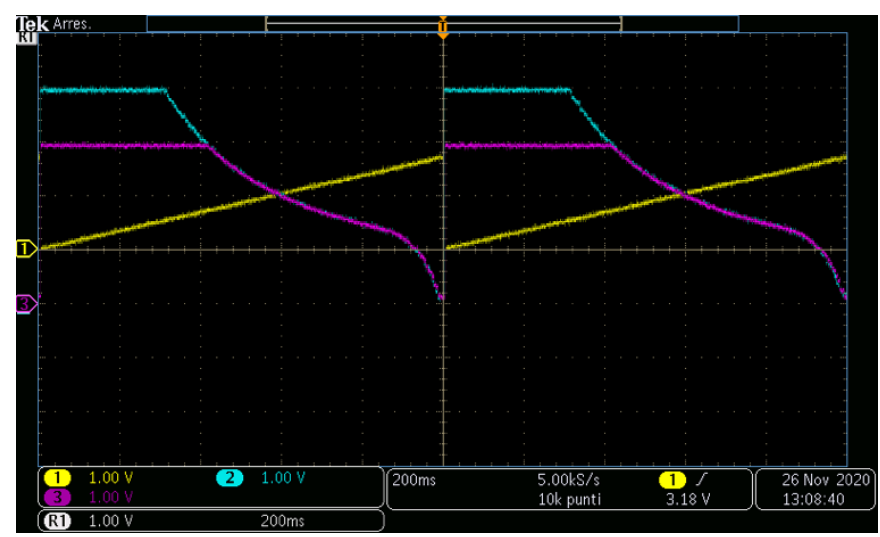

Figure 12. Oscilloscope screenshot (V-I curve in Operating Condition OC1). obtained by considering a PV system composed of a string of two B-PVUs is reported. In such a case the adopted distribution of the irradiance values $(S)$ characterizing the PV modules, the values of $\mathrm{I}_{\mathrm{DSMAx}}$ and the value of $T_{\text {ambient }}$ are the following: $[S]=([300 ; 200]) \mathrm{W} / \mathrm{m}^{2}, \quad I_{\text {DSMAX }}=4 \mathrm{~A}$ (turquoise curve), $I_{\text {DSMAX }}=3 \mathrm{~A}$ (pink curve) and $T_{\text {ambient }}=25^{\circ} \mathrm{C}$. The amplitude of the ramp signal (yellow curve), differently from the previous cases, varies from $0 \mathrm{~V}$ to $3.32 \mathrm{~V}$ which corresponds to B-PVU ramp voltage $V_{\mathrm{B}-\mathrm{PVU}}(t)$ ranging from 0 to the open circuit voltage $\mathrm{V}_{\mathrm{OC}}$ at $T=57.5^{\circ} \mathrm{C}$ of the considered string $\left(V_{\mathrm{OC}}=66 \mathrm{~V}\right)$.

In Figure 16 the experimental $I-V$ curves (black lines), acquired at the output port of the Power Block, are reported together with the theoretical ones (white lines) when $I_{\text {DSMAX }}=4$ A.

From the Figures it can be observed that the experimental and theoretical curves are nearly superimposed, thus confirming the excellent capability of the proposed solution of emulating BPVU behavior.

At the end, a Montecarlo analysis has been performed on the model, considering the irradiance measurement affected by an uncertainty (gaussian probability density function) equal to the

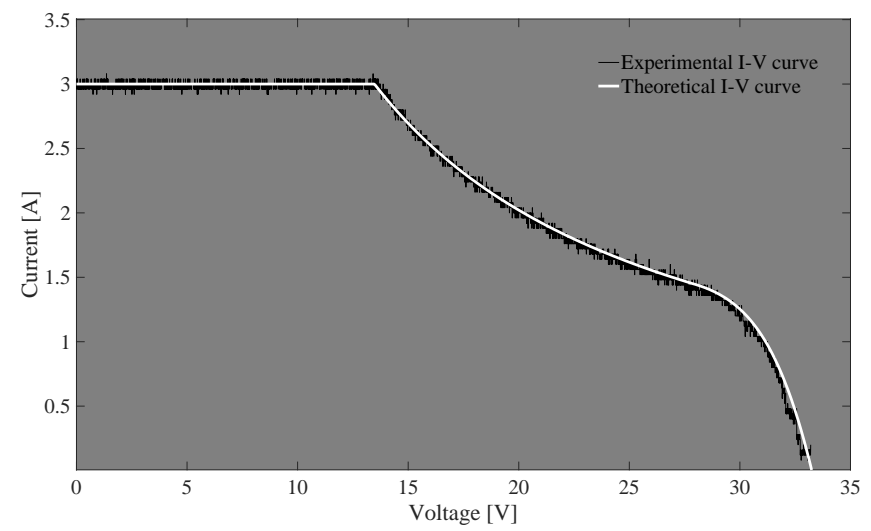

Figure 13. Comparison between experimental and theoretical $I-V$ curves: $S=200 \mathrm{~W} / \mathrm{m}^{2}, T_{\text {ambient }}=25^{\circ} \mathrm{C}, I_{\text {DSMAX }}=4 \mathrm{~A}$. 


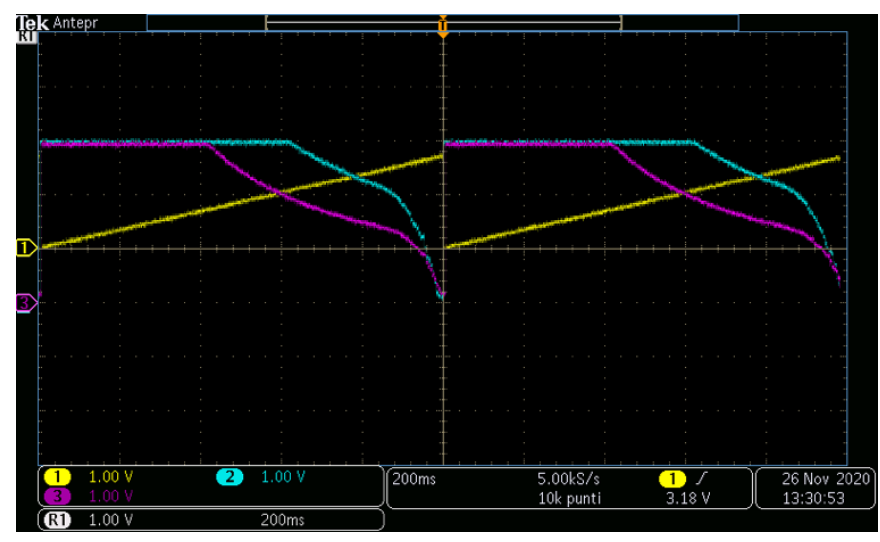

Figure 14. Oscilloscope screenshot ( $V$-I curve in Operating condition OC2).

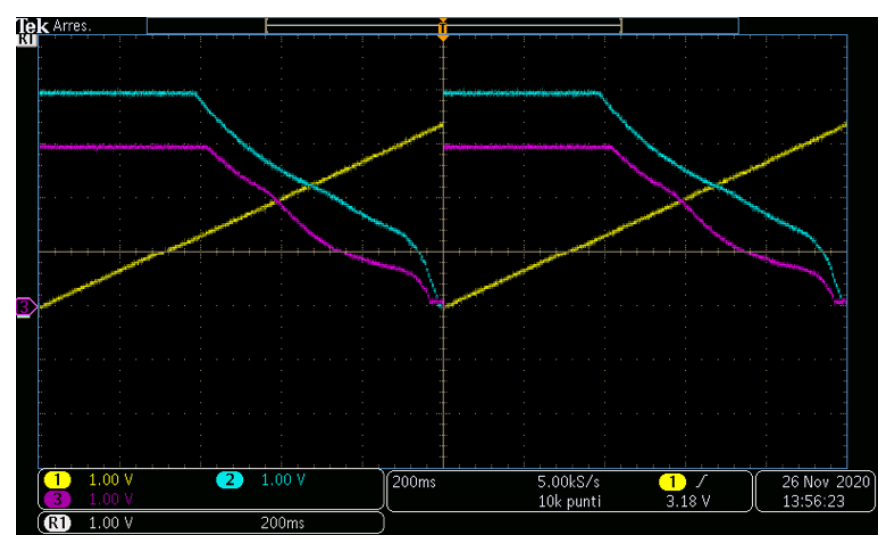

Figure 15. Oscilloscope screenshot ( $V-I$ curve in a string of two B-PVUs).

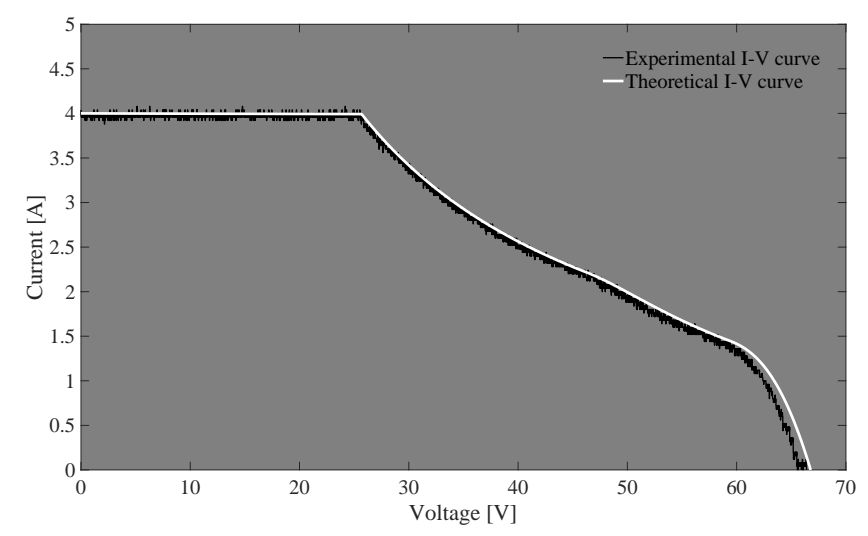

Figure 16. Comparison between experimental and theoretical $l-V$ curves: $S=(300,200) \mathrm{W} / \mathrm{m}^{2}, T_{\text {ambient }}=25^{\circ} \mathrm{C}, I_{\text {DSMAX }}=4 \mathrm{~A}$.

$5 \%$ of the reading, according to pyranometer datasheet available on the market. Moreover, a tolerance (uniform probability density function) equal to $3 \%$ has been associated with the value of IDSMAx; this value has been set according to the power tolerance declared in the specifications of the PV module SolarWorld SW 225. For each quantity 10000 realizations have been drawn according to the considered pdfs. The corresponding output of the maximum power point current $\mathrm{I}_{\mathrm{MPP}}$ has been achieved; the corresponding experimental pdf is shown in Figure 17. The observed mean value is equal to $7.60 \mathrm{~A}$ and the standard uncertainty is $0.38 \mathrm{~A}$ (about $5 \%$ ).

In Figure 18 the $I-V$ characteristics of B-PVU are shown. In particular, the portion of $I-V$ plain corresponding to the considered input quantities variability can be appreciated.

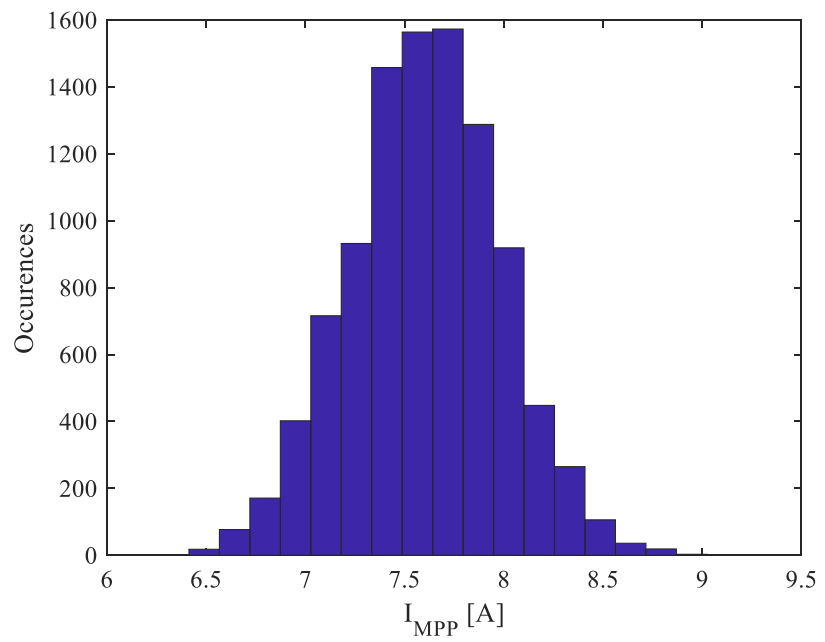

Figure 17. Observed experimental pdf of $I_{\text {MPP }}$ in Monte Carlo analysis.

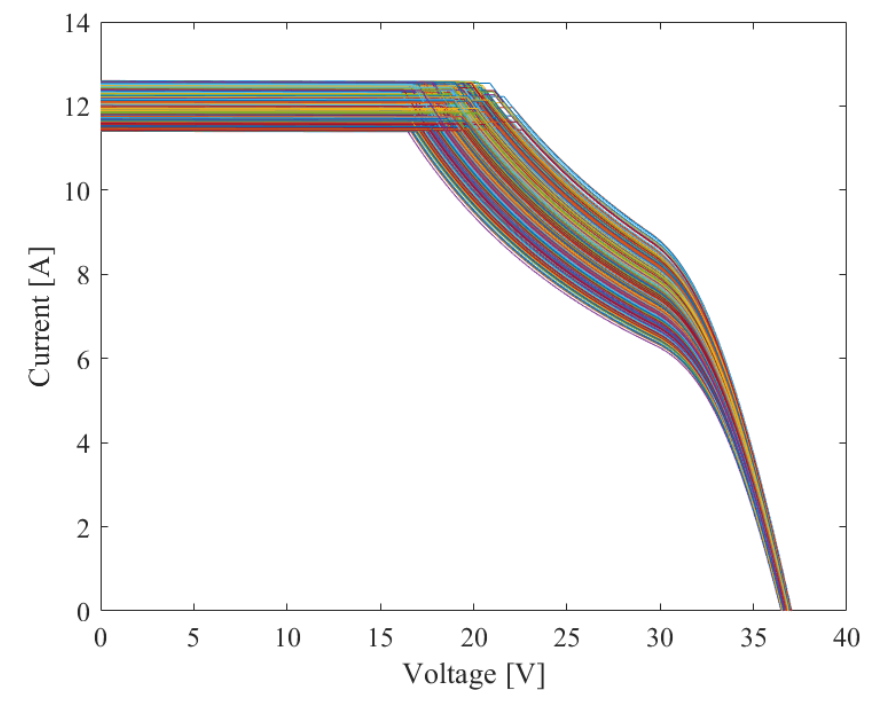

Figure 18. Set of $I-V$ characteristics obtained in Monte Carlo analysis.

\section{CONCLUSION}

In this paper, a Buck based DMPPT emulator has been presented and discussed. A detailed study was carried out in order to clearly understand the set of equations on which the mathematical model of the B-PVU is based on. The proposed emulator was designed to reproduce the $I-V$ characteristics at different values not only of the irradiance levels but also of the value of $I_{\text {DSMAx }}$. Moreover, the possibility to emulate a string of $\mathrm{B}-\mathrm{PVU}$ is also provided.

The high flexibility offered by the proposed solution allows to fully explore the performance of the DMPPT approach in academic laboratories. Moreover, the possibility to swap the value of $I_{\text {DSMAX }}$ allows the emulation of many Buck converters, which results in a consistent reduction in time and cost. In particular, the proposed device represents a suitable compromise between time and cost insofar as the inexpensive choice to adopt a commercial power supply is compensated by the possibility to emulate the behaviour of many commercial devices. The proposed experimental results fully confirm the validity of the proposed emulator. 


\section{REFERENCES}

[1] N. D. Kaushika, A. K. Rai, An investigation of mismatch losses in solar photovoltaic cell networks, Energy 325 (5) (2017), pp. 755759.

DOI: $10.1016 /$ j.energy.2006.06.017

[2] C. W. A. Baltus, J. A. Eikelboom, R. J. C. Van Zolingen, Analytical Monitoring of Losses in PV Systems, Proceedings of the 14th European Photovoltaic Solar Energy Conference, Barcelona, Spain, 1997, pp. 1547-1550.

[3] L. L. Bucciarelli, Jr., Power loss in photovoltaic arrays due to mismatch in cell characteristics, Sol. Cells 25(4) (1979), pp. 73-89. DOI: $10.1016 / 0038-092 X(79) 90121-\mathrm{X}$

[4] A. Bernieri, G. Betta, L. Ferrigno, M. Laracca, R. Schiano Lo Moriello, Electrical energy metering: Some challenges of the European Directive on Measuring Instruments (MID), Measurement 46(10) (2013), pp. 3347-3354.

DOI: $10.1016 /$ j.measurement.2013.06.025

[5] D. L. King, W. E. Boyson, J. A. Kratochvil, Analysis of factors influencing the annual energy production of photovoltaic systems, Proceedings of the 29th IEEE Photovoltaic Specialists Conference, New Orleans, LA, 19-24 May 2002, pp.1356-1361. DOI: $10.1109 /$ PVSC.2002.1190861

[6] G. Bucci F. Ciancetta, E. Fiorucci, A. Delle Femine, Thermographic and electrical characterization of a photovoltaic panel under partial shading conditions: a case study, Acta IMEKO 8(1) (2019), pp. 93-102.

DOI: $10.21014 /$ acta imeko.v8i1.609

[7] L. Cristaldi, M. Khalil, P. Soulatintork, A root cause analysis and a risk evaluation of PV balance of system failures, Acta IMEKO 6 (2017), pp. 113-120.

DOI: $10.21014 /$ acta imeko.v6i4.425

[8] P. Manganiello, M. Balato, M. Vitelli, A survey on mismatching and aging of PV modules: The closed loop, IEEE T. Ind. Electron. 62(11) (2015), pp. 7276-7286. DOI: $10.1109 /$ TIE.2015.2418731

[9] D. Sera, L. Mathe, T. Kerekes, S. V. Spataru, R. Teodorescu, On the perturb-and-observe and incremental conductance MPPT methods for PV systems, IEEE J. Photovolt. 3(3) (2013), pp. 1070-1078.

DOI: $10.1109 /$ JPHOTOV.2013.2261118

[10] C.-S. Chiu, T-S fuzzy maximum power point tracking control of solar power generation systems, IEEE T. Energy Conver. 25(4) (2010), pp. 1123-1132.

DOI: $10.1109 /$ TEC.2010.2041551

[11] R. Fontanella, D. Accardo, R. Schiano Lo Moriello, L. Angrisani, D. De Simone, An innovative strategy for accurate thermal compensation of Gyro Bias in inertial units by exploiting a novel Augmented Kalman Filter, Sensors 18(5) (2010).

DOI: $10.3390 / \mathrm{s} 18051457$

[12] A. Buonanno, M. D'Urso, G. Prisco, M. Felaco, L. Angrisani, M. Ascione, R. Schiano Lo Moriello, N. Pasquino, A new measurement method for through-the-wall detection and tracking of moving targets, Measurement 46(6)(2013), pp. 1834-1848. DOI: $10.1016 /$ j.measurement.2012.12.021

[13] J. Macaulay, Z. Zhou, A fuzzy logical-based variable step size P\&O MPPT algorithm for photovoltaic system, Energies 11(6) (2018) art. 1340 . DOI: $10.3390 /$ en 11061340

[14] S. Kolesnik, A. Kuperman, On the equivalence of major variablestep-size MPPT algorithms, IEEE J. Photovolt. 6(2) (2016), pp. 590-594.

DOI: $10.1109 /$ JPHOTOV.2016.2520212

[15] M. Sokolov, D. Shmilovitz, A modified MPPT scheme for accelerated convergence, IEEE T. Energy Conver. 23(4) (2008), pp. 1105-1107.

DOI: $10.1109 /$ TEC.2008.2001464

[16] M. Balato, L. Costanzo, M. Vitelli, Maximum power point tracking techniques, in Wiley Online Encyclopedia of Electrical and Electronics Engineering, John Wiley \& Sons, New Jersey, 2016, pp. 1-26.

DOI: $\underline{10.1002 / 0477134608 X . W 8299}$

[17] G. Kumar, M. B. Trivedi, A. K. Panchal, Innovative and precise MPP estimation using P-V curve geometry for photovoltaics, Appl. Energ. 138(15) (2015), pp. 640-647.

DOI: $10.1016 /$ j.apenergy.2014.10.041

[18] G. Kumar, A. K. Panchal, Geometrical prediction of maximum power point for photovoltaics, Appl. Energ. 119(15) (2014), pp. 237-245. DOI: $10.1016 /$ j.apenergy.2013.12.068

[19] N. Femia, G. Petrone, G. Spagnuolo, M. Vitelli, Optimization of perturb and observe maximum power point tracking method, IEEE T. Power Electr. 20(4) (20015), pp. 963-973. DOI: $10.1109 /$ TPEL.2005.850975

[20] D. Nguyen, B. Lehman, An adaptive solar photovoltaic array using model-based reconfiguration algorithm, IEEE T. Ind. Electron. 55(7) (2008), pp. 2644-2654. DOI: $10.1109 /$ TIE.2008.924169

[21] L. F. L. Villa, D. Picault, B. Raison, S. Bacha, A. Labonne, Maximizing the power output of partially shaded photovoltaic plants through optimization of the interconnections among its modules, IEEE J. Photovolt. 2(2) (2012), pp. 154-163. DOI: $10.1109 /$ JPHOTOV.2012.2185040

[22] H. Obane, K. Okajima, T. Oozeki, T. Ishii, PV system with reconnection to improve output under nonuniform illumination, IEEE J. Photovolt. 2(3) (2012), pp. 341-347. DOI: $10.1109 /$ JPHOTOV.2012.2188378

[23] H. Obane, K. Okajima, T. Oozeki, T. Ishii, PV system with reconnection to improve output under nonuniform illumination, IEEE Journal of Photovoltaics 2(3) (2012), pp. 341-347. DOI: $10.1109 /$ JPHOTOV.2012.2188378

[24] J. Storey, P. Wilson, D. Bagnall, Improved optimization strategy for irradiance equalization in dynamic photovoltaic arrays, IEEE T. Power Electr. 28(6) (2013), pp. 2946-2956.

DOI: $10.1109 /$ TPEL.2012.2221481

[25] E. R. Sanseverino, T. N. Ngoc, M. Cardinale, V. Li Vigni, D. Musso, P. Romano, F. Viola, Dynamic programming and Munkres algorithm for optimal photovoltaic arrays reconfiguration, Sol. Energy 122 (2015), pp. 347-358. DOI: $10.1016 /$ j.solener.2015.09.016

[26] D. La Manna, V. Li Vigni, E. R. Sanseverino, V. Di Dio, P. Romano, Reconfigurable electrical interconnection strategies for photovoltaic arrays: A review, Renewable and Sustainable Energ. Rev. 33 (2014), pp. 412-426. DOI: $10.1016 /$ i.rser.2014.01.070

[27] M. Balato, L. Costanzo, M. Vitelli, Reconfiguration of PV modules: a tool to get the best compromise between maximization of the extracted power and minimization of localized heating phenomena, Sol. Energy 138 (2016), pp. 105-118. DOI: $\underline{10.1016 / \text { i.rser.2014.01.070 }}$

[28] M. Balato, L. Costanzo, M. Vitelli, Series-Parallel PV array reconfiguration: Maximization of the extraction of energy and much more, Appl. Energ. 159(1) (2015), pp. 145-160.

DOI: $10.1016 /$ j.apenergy.2015.08.073

[29] M. Balato, L. Costanzo, M. Vitelli, Multi-objective optimization of PV arrays performances by means of the dynamical reconfiguration of PV modules connections, 2015 International Conference on Renewable Energy Research and Applications, ICRERA 2015, Palermo, Italy, 22-25 November 2015, pp. 16461650 .

DOI: $10.1109 /$ ICRERA.2015.7418685

[30] B. Burger, B. Goeldi, S. Rogalla, H. Schmidt, Module integrated electronics e an overview, 25th European Photovoltaic Solar Energy Conference and Exhibition, September 2010, Valencia (Spain), pp. 3700-3707. DOI: $10.4229 / 25$ thEUPVSEC2010-4EP.1.1

[31] Q. Li, P. Wolfs, A review of the single-phase photovoltaic module integrated converter topologies with three different DC link configurations, IEEE Trans. Power Electron. 23(3) (2008), pp 
1320-1333.

DOI: $10.1109 /$ TPEL.2008.920883

[32] S. B. Kjaer, J. K. Pedersen, F. Blaabjerg, A review of single-phase grid-connected inverters for photovoltaic modules, IEEE Trans. Ind. Appl. 41(5) (2005), pp. 1292-1306. DOI: $10.1109 /$ TIA.2005.853371

[33] N. Femia, G. Lisi, G. Petrone, G. Spagnuolo, M. Vitelli, Distributed maximum power point tracking of photovoltaic arrays: novel approach and system analysis, IEEE Trans. Ind. Electron. 55(7) (2008), pp. 2610-2621.

DOI: $10.1109 /$ TIE.2008.924035

[34] G.R. Walker, P.C. Sernia, Cascaded DC-DC converter connection of photovoltaic modules, IEEE Trans. Power Electron. 19(4) (2004), pp. 1130-1139.

DOI: $\underline{10.1109 / \text { TPEL.2004.830090 }}$

[35] E. Roman, R. Alonso, P. Ibanez, S. Elorduizapatarietxe, D. Goitia Intelligent PV module for grid-connected PV systems, IEEE Trans. Ind. Electron. 53(4) (2006), pp. 1066-1073. DOI: $10.1109 /$ TIE.2006.878327

[36] M. Balato, L. Costanzo, P. Marino, G. Rubino, L. Rubino, M. Vitelli, Modified TEODI MPPT technique: theoretical analysis and experimental validation in uniform and mismatching conditions, IEEE J. Photovolt. 7(2) (2017), pp. 604-613. DOI: 10.1109/JPHOTOV.2016.2634327

[37] C. A. Ramos-Paja, R. Gira, E. I. Arango-Zuluaga, Distributed maximum power point tracking in photovoltaic applications: active bypass DC/DC converter, Rev. Fac. Ing. Univ. Antioquia 65 (2012), pp. 32-44.

[38] M. Balato, M. Vitelli, A new control strategy for the optimization of Distributed MPPT in PV applications, International Journal of Electrical Power \& Energy Systems 62 (2014), pp. 763-773. DOI: $10.1016 /$ i.jijepes. 2014.05.032

[39] M. Balato, M. Vitelli, N. Femia, G. Petrone, G. Spagnuolo, Factors limiting the efficiency of DMPPT in PV applications, 2011 Int. Conf. Clean Electr. Power (ICCEP), Ischia, Italy, 14-16 June 2011, pp. 604-608.

DOI: $\underline{\text { 10.1109/ICCEP.2011.6036319 }}$
[40] M. Balato, L. Costanzo, M. Vitelli, DMPPT PV system: modeling and control techniques, Adv. Renew. Energ. Pow. Technol. 1 (2018), pp. 163-205.

DOI: $10.1016 /$ B978-0-12-812959-3.00005-8

[41] M. Balato, C. Petrarca, The impact of reconfiguration on the energy performance of the distributed maximum power point tracking approach in PV plants, Energies 13(6) (2020) art. 1511. DOI: $\frac{10.3390 / \text { en13061511 }}{2}$

[42] M. Balato, L. Costanzo, D. Gallo, C. Landi, M. Luiso, M. Vitelli, Design and implementation of a dynamic FPAA based photovoltaic emulator, Solar Energy 123 (2016), pp. 102-115. DOI: $10.1016 /$ i.solener.2015.11.006

[43] M. Balato, A. Liccardo, C. Petrarca, Dynamic Boost Based DMPPT Emulator, Energies 13(11) (2020) art. 2921. DOI: $10.3390 /$ en 13112921

[44] Moussa, I.; Khedher, A.; Bouallegue, A. Design of a Low-Cost PV Emulator Applied for PVECS. Electronics 2019, 8, 232.

[45] N. Ullah, F. Nisar, A. A. Alahmadi, Closed loop control of photo voltaic emulator using fractional calculus, IEEE Access 8 (2020), pp. 28880-28887. DOI: $10.1109 /$ ACCESS.2020.2971676

[46] N. Femia, G. Petrone, G. Spagnuolo, M. Vitelli, Power Electronics and Control Techniques for Maximum Energy Harvesting in Photovoltaic Systems, 2012, CRC Press, Taylor \& Francis group, ISBN: 978-1-4665-0690-9.

[47] Solarworld Website. Online [Accessed 09 June 2021] www.solarworldusa.com/ /media/www/files/datasheets/sunmoduleplus/sunmodule-solar-panel-225-mono-ds.pdf

[48] Kepco Website. Online [Accessed 09 June 2021] https://www.kepcopower.com/bop.htm

[49] Aduino Website. Online [Accessed 09 June 2021] https://www.arduino.cc/en/main/software 